\title{
PERAN PENDIDIKAN MATEMATIKA DALAM MENINGKATKAN SUMBER DAYA MANUSIA GUNA MEMBANGUN MASYARAKAT ISLAM MODERN
}

\author{
Firma Yudha ${ }^{1}$ \\ ${ }^{I}$ Pendidikan matematika Fakultas Dakwah Institut Agama Islam Ibrahimy Genteng Banyuwangi \\ Email: ${ }^{1}$ firmayudha123@ gmail.com
}

\begin{abstract}
Abstrak
Persaingan dunia pendidikan menjadi fokus utama didalam dunia global, termasuk pendidikan matematika didalamnya. Peran pendidikan matematika menjadi peran penting dimasyarakat dalam menyiapkan dan membentuk sumber daya manusia (SDM) yang memiliki beberapa kompetensi sebagai fondasi pendidikannya, seperti kompetensi analitik, kompetensi interpersonal, kemampuan untuk bertindak, kemampuan untuk memproses informasi, dan kemampuan untuk mengelola perubahan. Kompetensi-kompetensi tersebut dilatihkan kepada siswa selama proses pembelajaran berlangsung agar siswa memahami akan pentingnya pendidikan matematika dalam kehidupan seharihari dimasyarakat. Metode yang digunanakan dalam penelitian ini adalah metode analisis deskriptif kualitiatif, karena permasalahan penelitian ini alamiah dari kehidupan masyarakat islami, yang hasilnya dianalisis sesuai data yang diperoleh. Pada artikel ini dijelaskan peran pendidikan matematika dalam meningkatkan sumber daya manusia guna membangun masyarakat islam modern yaitu masyarakat yang menjalankan prinsip islami di tengah-tengah perkembangan zaman dan pesatnya perkembangan teknologi yang semakin modern. Karakter yang dibangun dalam belajar matematika misalnya kejujuran dan keterbukaan, konsisten, ketelitian, percaya diri, kerja keras, berjiwa wirausaha, berfikir logis, mandiri, ingin tahu dan cinta ilmu.
\end{abstract}

Kata Kunci: peran pendidikan matematika, kualitas sdm, masyarakat islami modren.

\begin{abstract}
The competition of education world becomes the main focus in global world including mathematics. The role of mathematics education become very importand in the middle of society in preparing and forming human resources that have several competencies as the fondation of their education, such as analytical competence, interpersonal competence, the bability to act, the ability to process an information and the ability to manage change. These competencies are trained to the student as long as the learning process to make them understand the importance of mathematics education in daily life of society. Beside that, it also carries out the standardized education. The method used in this study is the qualitative descriptive analysis method, because this research problem is natural from the life of Islamic society, the results of which are analyzed according to the data obtained. This article explains the role of mathematics education in increasing human resources to build a modern islamic society. The character in learning process becomes very importand in society, such as honesty, openness, consistence, accuracy, confidence, hard work, entrepreneurial spirit, logical thinking, independent, and love of science.
\end{abstract}

Keywords: The role of mathematics education, the quality of human resources, modern islamic sosiety

\section{PENDAHULUAN}

Pada zaman modern ini, perkembangan IPTEK (Ilmu Pengetahuan dan Teknologi) semakin maju dan berkembang. Dalam perkembangan ilmu pengetahuan dan teknologi ini bukan hanya pendidikan saja yang berkembang, namun bidang yang lain seperti bidang sosial, ekonomi, politik dan budaya juga mengalami kemajuan yang sangat pesat. Pemanfaatan teknologi dalam merupakan kebutuhan yang sangat mendesak untuk dipenuhi (Hasanah \& Maharany, 2017). Masing-masing tersebut tentulah sangat berpengaruh terhadap sumber daya yang dimiliki manusia, seperti sumber daya manusia, sumber daya alam, sumber 
daya waktu ataupun sumber daya lainnya. Pola perkembangan ilmu pengetahuan dan teknologi ini sangat perlu dan wajib didukung oleh sumber daya terkhusus sumber daya manusia, karena sumber daya manusia merupakan faktor utama yang dapat menentukan manusia sebagai sosial yang berpendidikan atau tidak, dengan sumber daya manusia juga manusia akan mempunyai modal yang sangat besar dalam dirinya.

Banyak cara untuk menumbuhkan dan memperkuat SDM (Sumber Daya Manusia) serta banyak pula strategi yang dapat dilakukan untuk mengelola sumber daya manusia, semisal kebutuhan utama sumber daya yang dipenuhi terlebih dahulu tentang kebutuhan akan ilmu pengetahuan dan teknologi. Kebutuhan ilmu pengetahuan dan teknologi disesuaikan dengan kemampuan yang dimiliki masing-masing individu sesuai dengan porsinya dan nantinya akan tepat guna menghasilkan sosial yang memiliki sumber daya manusia dan siap untuk bersaing secara internasional. Di sebuah wadah organisasi terutama di masyarakat islam modern dimana masyarakat menjalankan prinsip keislaman ditengah perkembangan zaman yang semakin modern, kebutuhan utama yang diprioritaskan dalam berinteraksi maupun berkolaborasi membutuhkan individu yang sumber daya manusia nya terpenuhi, karena nanti akan sangat berpengaruh terhadap proses pelaksanaan suatu kegiatan baik kegiatan formal maupun nonformal, dan juga akan berpengaruh terhadap hasil akhir dari sebuah kegiatan tersebut.

Dalam lingkungan pendidikan, salah satu pembelajaran yang mampu membentuk suatu masyarakat islam modern dan terdapat sosial yang sumber daya manusia terpenuhi adalah pembelajaran pendidikan matematika. Alasan mengapa pendidikan matematika mampu meningkatkan kualitas Sumber daya manusia dalam membangun masyarakat islami modern, karena di masyarakat khususnya masyarakat yang padat penduduk, tentunya dibutuhkannya kualitas individu guna membentuk masyarakat islam yang modern. Harapan yang ingin dicapai adalah menghasilkan SDM berkepribadian saleh, baik secara individu maupun sosial, dan dapat meningkatkan prestasi akademik serta profesionalisme di bidang masing-masing (Srijanti, dkk, 2007). Pendidikan matematika dapat membentuk, mendidik, melatih (baik melatih kesabaran, ketelitian, kecermatan, cara berfikir, kedisiplinan diri, dan lain-lain), mengapa juga dikatakan masyarakat islam, karena mayoritas penduduk beragama islam dan akan dibentuk sebuah masyarakat yang modern sesuai dengan zaman sekarang yang serba canggih karena ilmu pendidikan, ilmu pengeahuan dan teknologi yang semakin maju dan berkembang secara pesat.

\section{METODE}

Penelitian ini membahas tentang pentingnya pendidikan matematika didalam masyarakat guna membangun masyarakat yang modern islami. Subjek dalam penelitian ini adalah siswa SMP di Banyuwangi yang diambil secara acak sebanyak 30 Siswa. Pengumpulan data melaui wawancara dan observasi di lapangan. Hasil dalam penelitian ini berbentuk analisis deskriptif yang mampu merangkum hasil penelitian ini. Oleh sebab itu, penelitian yang dilakukan penulis yaitu dengan menggunakan pendekatan kualitatif. Denzin dan Lincoln (2000), menyatakan bahwa dalam penelitian kualitatif menekankan pada penggunaan dan pendekata yaitu interpretatif dan naturalistik. Penelitian kualitatif mempelajai sesuatu dalam setting alami mereka dan mencoba membuat pengertian atau interpretasi fenomena dalam konteks makna mereka. Metode penelitian kualitiatif sering disebut metode penelitian naturalistik karena penelitiannya dilakukan pada kondisi yang alamiah (natural setting), disebut juga sebagai metode etnography, karena pada walnya metode ini lebih banyak digunakan untuk penelitian bidang antropologi budaya, disebut sebagai metode kualitatif karena data yang terkumpul dan analisisnya lebih bersifat kualitatif (Sugiyono, 2017: 8).Kemudian Creswell (2012:16) mengungkapkan bahwa penelitian kualitatif yaitu: "qualitative research is best suited to address a research problem in which 
you do not know the variables and need to explore. The literature might yield little information about the phenomenon of study, and you need to learn more from participants through exploration" Menurut Creswell penelitian kualitatif paling cocok untuk mengatasi masalah penelitian dimana anda tidak tahu variabel dan perlu untuk mengeksplorasi.

\section{HASIL DAN PEMBAHASAN}

Matematika adalah disiplin pemikiran dan prosedur pengolahan logika, baik secara kuantitatif maupun kualitatif (Suherman, 2003). Sedangkan menurut Abdurrahman (2002) mengemukakan bahwa matematika adalah bahasa fungsi praktis simbolis untuk mengekspresikan hubungan kuantitatif dan spasial sementara fungsi teoritis adalah untuk memfasilitasi berfikir. Sehingga dapat dikatakan matmatika adalah suatu ilmu yang membuat manusia dapat berfikir berdasarkan logika. Manfaat Matematika dalam kehidupan sehari-hari: 1) melatih kesabaran, bisakah matematika dapat dikatakan untuk melatih kesabaran?tentu bisa, karena dalam mengerjakan matematika kita membutuhkan kesabaran dalam menyelesaikan permasalahan matematika yang terkadang rumit. 2) melatih kecermatan, ketelitian, dalam mengerjakan soal-soal matematika kita harus hati-hati, agar dapat menentukan bagaimana penyelesaian yang tepat dari permasalahan tersebut. Sehingga dengan matematika kita dapat melatih kecermatan dan ketelitian pada diri kita. 3) melatih cara berfikir, dengan kita mengerjakan soal-soal matematika kita dapat melatih cara berfikir, karena dengan mengerjakan soal matematika, kita dituntut untuk mnemukan jawaban yang benar dan tepat. Untuk mendapatkan jawaban yang benar dan tepat kita harus berfikir dengan keras cara untuk menyelesaikan soal tersebut dengan tepat. 4) Menjadi dasar pokok ilmu, mengapa matematika sebagai dasar pokok ilmu? Karena matematika adalah dasar dari ilmu menghitung, seperti fisika, kimia, akuntansi, dan lainnya. Dengan kita mengerti dasar atau pokoknya kita akan mudah paham dengan ilmu cabang lainnya. 5) melatih kedisiplinan diri, dalam mengertjakan soal-soal matematika harus sistematis berdasarkan urutan atau langkahlangkah yang teratur. Sehingga dengan mengerjakan soal matematika dapat belajar untuk mengerjakan sesuatu dengan cara teratur dan struktur. Maka dari itu, kita dapat mendisiplinkan diri. 6) membantu berdagang, matematika adalah ilmu berhitung, sehingga dapat digunakan untuk membantu berdagang. Matematika dapat digunakan untuk menghitung laba dan rugi, bahkan jika pedagang konvensional harus bisa matematika untuk menghitung uang kembalian pembeli.

Seorang guru haruslah menjadi sosok yang dapat dijadikan panutan oleh semua siswa/peserta didik. Guru yang professional merupakan guru yang sangat diminati oleh siswa, bukan hanya itu, tetapi guru yang mempunyai 4 kompetensi yaitu kompentesi pedagogik, profesional, kompetensi sosial dan kompetensi kepribadian. Dalam hal ini yang sangat berpengaruh terhadap proses belajar mengajar adalah kompetensi pedagogik dan profesional guru, yaitu cara mengajar guru di kelas dan juga kedisiplinan guru disekolah terutama di dalam proses belajar mengajar. Jadi kompetensi keduanya sangatlah berpengaruh terhadap siswa. selain itu semakin berkembangnya TIK (Tekhnologi informasi dan komunikasi) semakin berkembang pula pmbelajaran dikelas, guru dikelas bertugas sebagai fasilitator pembelajaran, sedangkan siswa sebagai pelaku utama didalam proses belajar, dalam hal ini bertujuan agar siswa dapat berfikir secara kreatif dan inovatif. Paradigma baru menuntut pembelajaran yang berpusat pada siswa, interaktif, bersifat menyelidiki, dalam konteks dunia nyata, berbasis tim (kooperatif), stimulasike segala indera dan alat multimedia dengan memanfaatkan berbagai teknologi pendidikan (Murtiyasa, 2015). Selain itu Dosen yang berperan diperguruan tinggi juga harus mengembangkan metode-metode pembelajaran yang menjadi ciri khas seorang dosen yang sesuai dengan pendidikan matematika, dalam hal ini dosen dituntut untukmengembangkan kompetensinya secara berkelanjutan agar mampu menjalankan tugasnya secara profesional. Pembelajaran matematika yang menggunakan 
tekhnologi pembelajaran secara umum ataupun khusus diperlukan manajemen sekolah yang dapat memfasilitasi hal tersebutdan peran serta kementerian pendidikan dan kebudayaan. Jika disekolah siswa kurang minat dengan pembelajaran matematika, maka harus dibangkitkan lagi minat siswa terhadap pembelajaran matematika, karena pada dasarnya matematika merupakan pelajaran yang yang tidak sedikit disukari siswa, bagi siswa yang malas berfikir logis dan berhitung, padahal sejatinya matematika jika didalam kelas pembelajarannya sangat menyenangkan dan selalu dikaitkan dengan kehidupan sehari-hari dan bermanfaat bagi kehidupan sehari-hari, maka minat siswa akan tinggi, itu adalah salah satu tugas utama guru didalam kelas.

Pendidikan matematika juga dapat digunakan dalam mempersiapkan peserta didik sebagai calon insan cendekia dan tenaga kerja terdidik dalam era MEA yaitu nilai-nilai atau karakter yang perlu dikembangkan berkaitan dengan matematika (Waluyo, 2012), berikut penjelasan masing-masing: a) kejujuran dan keterbukaan, peserta didik yang belajar matematika dengan sendirinya akan terlatih untuk jujur menggunakan definisi yang telah disepakati sebelumnya, lemma atau teorema untuk membuktikan teorema selanjutnya. Proses pembuktian ini juga dapat melatih keterbukaan menerima kritik dan saran sehingga diperoleh bukti yang lebih baik dan dapat dipertanggungajwabkan. b) konsisten, kekonsistenan peserta didik dapat dilatih dengan penggunaan definisi, lemma dan teorema. c) ketelitian, ketelitian sangat diperlukan dalam mempelajari matematika, sedangkan ketidaktelitian akan menyebabkan tidak terselesaikannya masalah. d) Percaya diri, terbentuk bila dalam belajar dan memanfaatkan matematika dapat paham. e) kerja keras, dilakukan supaya tugas/permasalahan terselesaikan. f) berjiwa wirausaha, perhitungan yang cermat sangat penting dalam berwirausaha. g) berfikir logis, kritis, kreatif dan inovatif, peserta didik akan berfikir atau melakukan sesuatu dengan cara logis untuk mendapatkan hasil baru dan mutakhir berdasarkan apa yang telah dimiliki. h) mandiri, tidak tergantung pada orang lain dalam menyelesaikan tugas. i) ingin tahu, berupaya untuk mengetahui lebih mendalam dari apa yang telah dipelajari, dilihat dan didengar. j) cinta ilmu, kecintaan kepada ilmu ditunjukkan dengan cara berfikir, bersikap dan bertindak.

Salah satu prinsip dasar dalam belajar matematika adalah prinsip kesetaraan tidak berarti setiap siswa memperoleh perlakuan yang sama dalam belajar matematika. Prinsip ini menyarankan setiap siswa dapat dan harus belajar matematika dengan mengakomodasi segala perbedaan karakterisik, perbedaan kemampuan awal, perbedaan kecepatan belajar, perbedan status sosial ekonomi, dan lain-lain. Siswa dengan kebutuhan khusus perlu dibantu dan didukung dengan berbagai hal misalnya dengan belajar dengan waktu yang lebih lama. Strategi lain yakni dengan menggunakan bantuan tekhnologi. Pada prinsip kurikulum, dimaksudkan bahwa kurikulum tidak sekedar kumpulan dari kegiatan yang dilakukan selama pembelajaran namun belum menenkankan pentungnya matematika. Matematika yang dipelajari selayaknya memfasilitasi siswa yang melanjutkan study sekaligus pemecahan masalah, baik untuk diterapkan disekolah, dirumah dan dunia kerja. Susunan materi-materi juga saling terhubung, sehingga mudah mempelajari dari satu konsep ke konsep yang lainnya.

Kurikulum yang dinyatakan secara jelas akan memberikan kemudahan bagi guru untuk menerapkannya, termasuk memprtimbangkannya ketika mengampu lintas kelas. Prinsip pengajaran, menelankan bahwa pembelajaran yang dilaksanakan dalam mata pelajaran matematika yang sesuai dengan tujuannya, memerlukan penguasaan konsep prasyarat dan diperlukan siswa yang selanjutnya "menantang" siswa, juga mendukung siswa untuk balajar mengenai matematika, siswa sebagai peserta didik, dan strategi pembelajaran. proses pengajaran secara terus menerus memotret perkembangan dan kemajuan peserta didik. Prinsip pembelajaran (learning prinsiple), siswa harus memperlajari matematika dengan pemahaman, membangun pengetahuan yang baru secara aktif berdasarkan pengalaman pengetahuan awal siswa. Belajar sampai memperoleh pemahaman merupakan hal esensial, 
yang merupakan komponen utama kemampuan. Sesorang dapat menerapkan suatu konsep

untuk memecahkan masalah dapat terjadi hanya jika konsep tersebut dipahami dengan baik oleh siswa. prinsip penilaian, penilaian meningkatkan hasil belajar siswa. assesmen yang baik meningkatkan belajar siswa dengan berbagai cara. Tugas dalam assesmen membawa pesan kepada siswa tentang pengetahuan dan kemampuan apa yang berharga selama proses pembelajaran. masukan dari tugas-tugas membantu siswa menyeting tujuan dan perbaikan cara belajar. Hasil assesmen digunakan untuk membuat kebijakan terkait dengan pembelajaran dan hasil assesmen digunakan untuk meningkatkan kualitas pembelajaran. prinsip tekhnologi, tekhnologi penting dalam pembelajaran matematika untuk meningkatkan kualitas pembelajaran. dalam pembelajaran matematika, teknologi diharapkan dapat mendukung pembelajran yang efektif. Dengan mentaati prinsip ini, pembelajaran matematika melatih pemanfaatan dan penguasaan teknologi informasi kepada siswa. Hubungan antara keterlaksanaan prinsip pendidikan matematika dengan kompetensi lebih jelas ditampilkan dalam Tabel 1 berikut

Tabel 1 Hubungan antara keterlaksanaan prinsip pendidikan matematika dengan kompetensi

\section{Prinsip pendidi-kan} matema-tika

\begin{tabular}{|c|c|c|c|c|c|}
\hline \multirow{2}{*}{\multicolumn{2}{|c|}{$\begin{array}{l}\text { Prinsip } \\
\text { kesetara-an }\end{array}$}} & & & informasi & berubah \\
\hline & & $\begin{array}{l}\text { Komunikasi, } \\
\text { kolaborasi, } \\
\text { kepemimpinan } \\
\text { dan } \\
\text { tanggungjawa } \\
\text { b }\end{array}$ & & & \\
\hline $\begin{array}{l}\text { Prinsip kuriku- } \\
\text { lum }\end{array}$ & $\begin{array}{l}\text { Berfikir } \\
\text { kritis, } \\
\text { pemecahan } \\
\text { masalah, } \\
\text { membuat } \\
\text { keputusan, } \\
\text { penelitian } \\
\text { dan } \\
\text { penemuan }\end{array}$ & $\begin{array}{l}\text { Komunikasi, } \\
\text { kolaborasi, } \\
\text { kepemimpinan } \\
\text { dan tanggung } \\
\text { jawab }\end{array}$ & $\begin{array}{l}\text { Inisiatif, } \\
\text { kemandi- } \\
\text { rian, } \\
\text { produkti- } \\
\text { vitas }\end{array}$ & $\begin{array}{l}\text { Literasi } \\
\text { informasi, } \\
\text { literasi media, } \\
\text { operasi dan } \\
\text { konsep } \\
\text { tenologi } \\
\text { komunikasi } \\
\text { dan informasi }\end{array}$ & $\begin{array}{l}\text { Kreatif/ } \\
\text { inovatif }\end{array}$ \\
\hline $\begin{array}{l}\text { Prinsip pengaja- } \\
\text { ran }\end{array}$ & $\begin{array}{l}\text { Berfikir } \\
\text { kritis, } \\
\text { pemecahan } \\
\text { masalah, } \\
\text { membuat } \\
\text { keputusan, } \\
\text { penelitian } \\
\text { dan } \\
\text { penemuan }\end{array}$ & $\begin{array}{l}\text { Komunikasi, } \\
\text { kolaborasi, } \\
\text { kepemimpinan } \\
\text { dan tanggung } \\
\text { jawab }\end{array}$ & $\begin{array}{l}\text { Inisiatif, } \\
\text { kemandi- } \\
\text { rian, } \\
\text { produkti- } \\
\text { vitas }\end{array}$ & & $\begin{array}{l}\text { Kreatif/ } \\
\text { inovatif }\end{array}$ \\
\hline $\begin{array}{l}\text { Prinsip } \\
\text { pembela-jaran }\end{array}$ & $\begin{array}{l}\text { Berfikir } \\
\text { kritis, } \\
\text { pemecahan } \\
\text { masalah, } \\
\text { membuat } \\
\text { keputusan, } \\
\text { penelitian } \\
\text { dan } \\
\text { penemuan }\end{array}$ & $\begin{array}{l}\text { Komunikasi, } \\
\text { kolaborasi, } \\
\text { kepemimpinan } \\
\text { dan tanggung } \\
\text { jawab }\end{array}$ & $\begin{array}{l}\text { Inisiatif, } \\
\text { kemandi- } \\
\text { rian, } \\
\text { produkti- } \\
\text { vitas }\end{array}$ & & $\begin{array}{l}\text { Kreatif/ } \\
\text { inovasi, } \\
\text { pembelajaran } \\
\text { adaptif, } \\
\text { flesibilitas }\end{array}$ \\
\hline $\begin{array}{l}\text { Prinsip } \\
\text { penilaian }\end{array}$ & $\begin{array}{l}\text { Berfikir } \\
\text { kritis, }\end{array}$ & $\begin{array}{l}\text { Komunikasi, } \\
\text { kolaborasi, }\end{array}$ & $\begin{array}{l}\text { Inisiatif, } \\
\text { kemandirian, }\end{array}$ & $\begin{array}{l}\text { Literasi } \\
\text { informasi, }\end{array}$ & $\begin{array}{l}\text { Kreatif/ } \\
\text { inovasi, }\end{array}$ \\
\hline
\end{tabular}

\section{Kompetensi}

\begin{tabular}{lllll}
\multicolumn{5}{c}{ Kompetensi } \\
Analitik & Interpersonal & Bertindak & $\begin{array}{c}\text { Memproses } \\
\text { informasi }\end{array}$ & $\begin{array}{c}\text { (Untuk) } \\
\text { berubah }\end{array}$
\end{tabular}

Komunikasi,

kolaborasi,

kepemimpinan

tanggungjawa 政

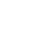

(n)

(n)




\begin{tabular}{|c|c|c|c|c|c|}
\hline & $\begin{array}{l}\text { pemecahan } \\
\text { masalah, } \\
\text { membuat } \\
\text { keputusan, } \\
\text { penelitian } \\
\text { dan } \\
\text { penemuan }\end{array}$ & $\begin{array}{l}\text { kepemimpinan } \\
\text { dan tanggung } \\
\text { jawab }\end{array}$ & $\begin{array}{l}\text { produkti- } \\
\text { vitas }\end{array}$ & $\begin{array}{l}\text { literasi media, } \\
\text { operasi dan } \\
\text { konsep } \\
\text { teknologi } \\
\text { komunikasi } \\
\text { dan informasi }\end{array}$ & $\begin{array}{l}\text { pembelajaran } \\
\text { adaptif, } \\
\text { flesibilitas }\end{array}$ \\
\hline $\begin{array}{l}\text { Prinsip } \\
\text { teknologi }\end{array}$ & $\begin{array}{l}\text { Berfikir } \\
\text { kritis, } \\
\text { pemecahan } \\
\text { masalah, } \\
\text { membuat } \\
\text { keputusan, } \\
\text { penelitian } \\
\text { dan } \\
\text { penemuan }\end{array}$ & $\begin{array}{l}\text { Komunikasi, } \\
\text { kolaborasi, } \\
\text { kepemimpinan } \\
\text { dan tanggung } \\
\text { jawab }\end{array}$ & $\begin{array}{l}\text { Inisiatif, } \\
\text { kemandi- } \\
\text { rian, } \\
\text { produkti- } \\
\text { vitas }\end{array}$ & $\begin{array}{l}\text { Literasi } \\
\text { informasi, } \\
\text { literasi media, } \\
\text { operasi dan } \\
\text { konsep } \\
\text { teknologi } \\
\text { komunikasi } \\
\text { dan informasi }\end{array}$ & $\begin{array}{l}\text { Kreatif/ } \\
\text { inovasi, } \\
\text { pembelajaran } \\
\text { adaptif, } \\
\text { flesibilitas }\end{array}$ \\
\hline
\end{tabular}

Prinsip pendidikan matematika diatas, bahwa dalam melaksanakan pembelajaran sesuai dengan prinsip,kompetensi anailitik, interpersonal, memproses informasi dan keinginan untuk berubah yang dikuasai. Selain itu dari Tabel 1 sebelumnya dapat diperkuat dengan tabel 2 berikut ini.

Tabel 2 Hubungan antara keterlaksanaan standar proses pendidikan matematika dengan kompetensi

\begin{tabular}{|c|c|c|c|c|c|}
\hline \multirow{2}{*}{$\begin{array}{c}\text { Standar } \\
\text { proses }\end{array}$} & \multicolumn{5}{|c|}{ Kompetensi } \\
\hline & Analitik & $\begin{array}{l}\text { Interper- } \\
\text { sonal }\end{array}$ & Bertindak & $\begin{array}{c}\text { Memproses } \\
\text { informasi }\end{array}$ & (untuk) berubah \\
\hline $\begin{array}{l}\text { Pemecahan } \\
\text { masalah }\end{array}$ & $\begin{array}{l}\text { Berfikir } \\
\text { kristis, } \\
\text { pemecahan } \\
\text { masalah, } \\
\text { membuat } \\
\text { keputusan, } \\
\text { penelitian dan } \\
\text { penemuan }\end{array}$ & $\begin{array}{l}\text { Tanggung } \\
\text { jawab }\end{array}$ & $\begin{array}{l}\text { Inisiatif dan } \\
\text { mandiri }\end{array}$ & $\begin{array}{l}\text { Literasi } \\
\text { informasi }\end{array}$ & $\begin{array}{l}\text { Kreatif dan } \\
\text { inovatif, fleksibili- } \\
\text { tas }\end{array}$ \\
\hline $\begin{array}{l}\text { Penalaran } \\
\text { dan } \\
\text { pembuktian }\end{array}$ & $\begin{array}{l}\text { Berfikir } \\
\text { kristis, } \\
\text { pemecahan } \\
\text { masalah, } \\
\text { membuat } \\
\text { keputusan, } \\
\text { penelitian dan } \\
\text { penemuan }\end{array}$ & $\begin{array}{l}\text { Tanggung } \\
\text { jawab }\end{array}$ & Inisiatif & $\begin{array}{l}\text { Literasi } \\
\text { informasi }\end{array}$ & $\begin{array}{l}\text { Kreatif dan } \\
\text { inovatif, fleksibili- } \\
\text { tas }\end{array}$ \\
\hline Komnikasi & $\begin{array}{l}\text { Berfikir } \\
\text { kristis, } \\
\text { pemecahan } \\
\text { masalah, } \\
\text { membuat } \\
\text { keputusan, } \\
\text { penelitian dan } \\
\text { penemuan }\end{array}$ & $\begin{array}{l}\text { Komunikas } \\
\text { i, tanggung } \\
\text { jawab }\end{array}$ & & $\begin{array}{l}\text { Literasi } \\
\text { informasi }\end{array}$ & $\begin{array}{l}\text { Kreatif dan } \\
\text { inovatif, fleksibili- } \\
\text { tas }\end{array}$ \\
\hline Koneksi & $\begin{array}{l}\text { Berfikir } \\
\text { kristis, } \\
\text { pemecahan }\end{array}$ & $\begin{array}{l}\text { Komunikas } \\
\text { i, tanggung } \\
\text { jawab }\end{array}$ & & $\begin{array}{l}\text { Literasi } \\
\text { informasi }\end{array}$ & $\begin{array}{l}\text { Kreatif dan } \\
\text { inovatif, fleksibili- } \\
\text { tas }\end{array}$ \\
\hline
\end{tabular}




\begin{tabular}{|c|c|c|c|c|c|}
\hline & $\begin{array}{l}\text { masalah, } \\
\text { membuat } \\
\text { keputusan, } \\
\text { penelitian dan } \\
\text { penemuan }\end{array}$ & & & & \\
\hline Representasi & $\begin{array}{l}\text { Berfikir } \\
\text { kristis, } \\
\text { pemecahan } \\
\text { masalah, } \\
\text { membuat } \\
\text { keputusan, } \\
\text { penelitian dan } \\
\text { penemuan }\end{array}$ & $\begin{array}{l}\text { Komunikas } \\
\text { i, tanggung } \\
\text { jawab }\end{array}$ & $\begin{array}{l}\text { Inisiatif, } \\
\text { kemandirian, } \\
\text { produk- } \\
\text { tivitas }\end{array}$ & $\begin{array}{l}\text { Literasi } \\
\text { informasi }\end{array}$ & $\begin{array}{l}\text { Kreatif dan } \\
\text { inovatif, fleksibili- } \\
\text { tas }\end{array}$ \\
\hline
\end{tabular}

Dari standar diproses atas, guru dan siswa wajib memilih beberapa strategi yang akan digunakan dalam pembelajaran. pembelajaran yang dilakukan hendaknya tidak hanya menekankan pada lower order thinking, namun juga perlunya pembelajaran Higher Order Thinking Skills (HOTS). Pembelajaran HOTS dilaksanakan dengan memberikan penekanan partisipasi aktif siswa dan didesain mulai dari penentuan tujuan pebelajaran. Selain itu alur belajar juga penting untuk diperhatikan ketika merumuskan tujuan pembelajaran (Retnowati, 2017). Tujuan pembelajaran bukan hanya untuk kegiatan pembelajaran, namun juga sebagai keperluan asesmen. Selain tujuan, ada juga penilaian. Penilain disini untuk melihat kemampuan siswa, keberhasilan siswa. Menurut Retnawati, dkk (2007) penilaian sangat besar manfaatnya, diantaranya untuk memotret kemampuan siswa untuk menilai keberhasilan pembelajaran yang dilaksanakan, memperoleh masukan strategi belajar siswa.

Pembelajaran yang memenuhi standar proses diatas, misalnya pembelajaran berbasis masalah, dan pembelajaran berbasis proyek (Apino \& Retnowati, 2018).Pembelajaran berbasis masalah dalam hal ini termasuk pembelajaran matematika. Sudah dijelaskan diatas bahwa dalam belajar matematika karakter wajib yang harus dimiliki siswa merupakan sesuatu hal yang dapat dilakukan siswa untuk berlangsungnya belajar. Dalam hal ini sama dengan kita bermasyarakat di lingkungan islam modern ini. Bermasyarakat tentunya kita harus mempunyai pegangan hidup untuk kelangsungan hidup kita, dengan tujuan agar hidup dimasyarakat penuh dengan kenyamananan dan ketentraman yang dibekali oleh ilmu Pengetahuan dan didasarkan pada sumber daya manusia yang memadai.

Masyarakat modern terbentuk setelah adanya masa industrialisasi pada abad 17. Adanya pengaruh ini menyebabkan munculnya semangat revolusi industri yang menumbangkan kekuasaan raja absolut. Kemenangan rakyat atau penduduk atas raja ini menandai perhatian teknologi dan ilmu pengetahuan untuk kepentingan rakyat banyak. Sistem pemerintahan pada masa ini berubah dari sistem kekuasaan absolut kebentuk baruyang lebih berpihak pada rakyat, seperti sistem demokrasi, sistem pemerintahan republik, atau federal (Adon, 2017: 53).

\section{KESIMPULAN DAN SARAN}

Peran pendidikan matematika dalam membangun masyarakat islami yang modern adalah melatih siswa dalam pembelajaran yang sesuai dengan pola pembelajaran wajib dan harus memiliki karakter pembelajaran matematika yang nantinya mampu diterapkan dalam kehidupan shari-hari di masyarakat dengan karakter tersebut. Selain itu melatih kompetensi seperti kompetensi analitik, interpersonal, bertindak, memproses informasi dan mengelola perubahan. Kompetensi tersebut dapat dicapai melalui proses pendidikan dan untuk pendidikan maematika dilaksanakan melalui prinsip dan standar tertentu. 
Selain itu peran seorang guru yang keratif dan inovatif sangat penting perannya bagi siswa. Dukungan dari berbagai pihak perlu dilakukan sebagai pendorong terselenggaranya pendidikan, sehingga usaha untuk meningkatkan kualitas sumber daya manusia sebagai pembangunan masyarakat islami modern terpenuhi. Rekomendasi penelitian selanjutnya adalah perlu adanya penelitian lebih lanjut mengenai langkah kongkrit terkait dengan kegiatan di kelas sebagai bentuk realisasi penelitian ini.

\section{DAFTAR RUJUKAN}

Nasrullah, A. (2017). Sosiologi perkotaan. Bandung: CV Pustaka setia.

Apino, E. \& Retnawati, H. (2008). Desain pembelajaran matematika untuk melatihkan higger order thinking skills. Yogyakarta: Parama.

Creswell, J. W. (1994). Research Design Qualitative \& Quantitative Approach. London: Publication.

Hasana, S. N. \& Maharany, E. R. (2017). Pengembangan Multimedia Menggunakan Visual Basic for Application (VBA) untuk Meningkatkan Profesionalisme Guru Matematika. Jurnal Pendidikan Matematika Universitas Islam Malang, 3(2), 2442-4668.

Hwang, W. Y. (2007). Multiple representation skillsand creativity effect on mathematical problem solving using a multimedia whiteboard system. Education Technology \& Society, 10 (2), 191-212.

Jailani \& Retnawati, H. (2016). The challenges of junior high school mathematic teacher in implementing the problem-based learning for improving the higher-order thinking skills. The online journal of conseling and education, 5(3), 1-13.

Murtiyasa. (2015). Tantangan pembelajaran matematika di Era Global. Prosiding seminar nasional matematika dan pendidikan matematika UMS 2015. Surakarta: Universitas Muhammadiyah Surakarta.

Retnawati, H., Hadi. S., \& Nugraha, A. C. (2016). Vocational high school teacher's difficulties in implementing the assessment in curriculum 2013 in Yogyakarta Province of indonesia. International journal of instruction, 9(1).

Srijanti, Purwanto, S. K., \& Pramono, W. (2007). Etika Membangun Masyarakat Islam Modern. Yogyakarta: Graha Ilmu.

Sugiyono. (2017). Metode Penelitian Kuantitatif, Kualitatif dan R\&D. Bandung: ALFABETA.

Waluya. S. B. (2012). Peran matematika dan pendidikan matematika dakam membangunkarakter bangsa. Prosiding seminarnasional matematika dan pendidikan matematika UNY 10 November 2015. Yogyakarta: FMIPA UNY.

Yee, S. P., \& Bostic, J. D. (2014). Developing a contextualization of student's mathematical problem solving. Journal of mathamatical behavior, 36, 1-19. 